\title{
Effects of Ni and Cr Contents on Fatigue Crack Growth Properties of SUS316-based Stainless Steels in High-pressure Gaseous Hydrogen
}

\author{
Shinichi OHMIYA* and Hideki FUJII \\ Steel Research Laboratories, Nippon Steel Corporation, Shintomi, Futtsu-shi, Chiba, 293-8511 Japan. \\ E-mail: ohmiya.shinichi@nsc.co.jp
}

(Received on July 19, 2011; accepted on November 8, 2011)

\begin{abstract}
Fatigue crack growth tests were carried out in high-pressure gaseous hydrogen at $90 \mathrm{MPa}$ at room temperature for SUS316-based stainless steels containing different amounts of $\mathrm{Ni}$ and $\mathrm{Cr}$, and the effects of these alloying elements on fatigue crack propagation were investigated. The fatigue crack growth rate of the SUS316-based steels with a Ni content lower than 12 mass \% was accelerated in hydrogen gas with decreasing $\mathrm{Ni}$ content. The $\mathrm{Cr}$ content had little effect on the fatigue crack growth rate in hydrogen gas. The combined effect of the $\mathrm{Ni}$ and $\mathrm{Cr}$ contents on the fatigue crack growth rate was closely related to Md30 and a modified $\mathrm{Ni}$ equivalent, $[\mathrm{Ni}]+0.37[\mathrm{Cr}]$, where $[\mathrm{Ni}]$ and $[\mathrm{Cr}]$ are the $\mathrm{Ni}$ and $\mathrm{Cr}$ contents, respectively. The fatigue crack growth rate in the second region in the da/dN- $\Delta \mathrm{K}$ relationship for SUS316-based stainless steels can be estimated with the Paris equation, da/dN $=C(\Delta K)^{\mathrm{m}}$, and $C=8 \cdot 10^{-11} \cdot \exp$ (0.0235. Md30) in steels with $\mathrm{Md} 30>-95^{\circ} \mathrm{C}$. No clear degradation ascribable to high pressure hydrogen gas was observed in steels with $\mathrm{Md} 30 \leq-95^{\circ} \mathrm{C}$ or $[\mathrm{Ni}]+0.37[\mathrm{Cr}] \geq 17.5$ mass $\%$. Fatigue cracks propagated mainly in the $\gamma$ phase, and the $\alpha^{\prime}$ deformation induced martensite phase sometimes became the crack propagation path in tested steels with low $\gamma$ phase stability. Faceted fracture surfaces consisting of the $\{111\} \gamma$ plane and $\alpha^{\prime}$ martensite were observed at the fatigue fracture surfaces and considered to be formed as a result of hydrogen gas embrittlement at or near the interphase boundaries between the two phases, where the hydrogen concentration was considered to be high.
\end{abstract}

KEY WORDS: stainless steel; fatigue crack growth; hydrogen embrittlement; Ni content; Cr content; high pressure hydrogen gas.

\section{Introduction}

Various actions to reduce $\mathrm{CO}_{2}$ emissions, which are believed to be the most influential factor causing global warming, have been taken in industrial fields. For example, the automotive industry, which accounts for a large proportion of $\mathrm{CO}_{2}$ emissions, has achieved some innovative developments in this regard during the last two decades, such as hybrid vehicles, including the plug-in type, clean diesels, and electric vehicles, among others. These vehicles are already or are about to be in practical use and are expected to contribute to reducing $\mathrm{CO}_{2}$ and other harmful gas emissions substantially. Another approach being pursued is to establish a clean, hydrogen-based society, in which hydrogen fuel cell vehicles (FCVs) and hydrogen filling stations (HSs) will play leading roles. According to a recent scenario released in March 2010 by the Fuel Cell Commercialization Conference of Japan, ${ }^{1)}$ an FCV market is expected to be formed by 2015. To accomplish that and to expand the market further after 2015, various issues need to be solved. One of them is to expand the range of materials that can be used for high-pressure hydrogen gas supply, including pipes, vessels, pumps and valves for both FCVs and HSs. All of these parts are exposed to compressed high-pressure hydrogen gas.

Evaluation of the mechanical properties of materials in high-pressure gaseous hydrogen was extensively conducted in the early 1970 s in the United States, and a lot of data on high and low cycle fatigue life properties were obtained for various materials. $^{2-5)}$ However, a few data on fatigue crack growth properties in high-pressure hydrogen gas were reported. ${ }^{2,3)}$ It took almost 30 years until available data on the fatigue crack growth rate of commercial stainless steels in high-pressure hydrogen gas were reported by the authors in the 2000s. ${ }^{6-9)}$

The current codes and standards related to FCVs and HSs such as Japan Automobile Research Institute Standard (JARI S) 001 for $35 \mathrm{MPa}$-class onboard hydrogen fuel tanks ${ }^{10)}$ and JARI S002 for their installation on vehicles ${ }^{10}$ and Kouatsu-gas Hoan Kyoukai (The High Pressure Gas Safety Institute of Japan) Standard (KHKS) 0128 for onboard hydrogen fuel tanks up to nominal pressure of $70 \mathrm{MPa}^{11)}$ allow only two kinds of materials to be used for these applications. Japan Industrial Standard (JIS) SUS316L stainless steel is one of them and has been confirmed to be very durable against hydrogen. Deterioration of its mechan- 
Table 1. Chemical compositions of steels used (mass $\%$ ).

\begin{tabular}{cccccccccccc}
\hline No. & & $\mathrm{C}$ & $\mathrm{Si}$ & $\mathrm{Mn}$ & $\mathrm{P}$ & $\mathrm{S}$ & $\mathrm{Ni}$ & $\mathrm{Cr}$ & $\mathrm{Mo}$ & $\mathrm{Cu}$ & $\mathrm{N}$ \\
\hline 1 & $17.1 \mathrm{Cr}-9.8 \mathrm{Ni}$ & 0.018 & 0.54 & 1.01 & 0.023 & 0.0005 & 9.82 & 17.05 & 2.10 & 0.23 & 0.0400 \\
2 & $17.1 \mathrm{Cr}-10.7 \mathrm{Ni}$ & 0.018 & 0.54 & 1.01 & 0.022 & 0.0005 & 10.73 & 17.09 & 2.10 & 0.23 & 0.0397 \\
3 & $17.1 \mathrm{Cr}-11.7 \mathrm{Ni}$ & 0.017 & 0.54 & 1.01 & 0.022 & 0.0005 & 11.73 & 17.10 & 2.11 & 0.22 & 0.0395 \\
4 & $16.1 \mathrm{Cr}-10.7 \mathrm{Ni}$ & 0.017 & 0.53 & 1.02 & 0.021 & 0.0005 & 10.74 & 16.07 & 2.06 & 0.21 & 0.0399 \\
5 & $18.1 \mathrm{Cr}-10.8 \mathrm{Ni}$ & 0.017 & 0.53 & 1.00 & 0.022 & 0.0005 & 10.77 & 18.13 & 2.07 & 0.22 & 0.0394 \\
\hline
\end{tabular}

ical properties in high-pressure hydrogen gas is limited if its chemical composition is correct and no serious segregation of alloying elements occurs. ${ }^{6-9,12,13)}$

However, it has also been observed that segregation of alloying elements in stainless steels, especially $\mathrm{Ni}$, sometimes causes degradation of tensile and fatigue properties in hydrogen gas. ${ }^{12-14)}$ The authors previously investigated the effect of $\mathrm{Ni}$ and $\mathrm{Cr}$ contents on tensile properties in gaseous hydrogen at $45 \mathrm{MPa}$ pressure at room temperature and $-40^{\circ} \mathrm{C}$ using specially prepared SUS316-based stainless steels having 9.8 to 11.7 mass\% $\mathrm{Ni}$ and 16.1 to $18.1 \mathrm{mass} \% \mathrm{Cr}$, with Mo and other impurity contents kept to the same levels as those in conventional SUS316L. ${ }^{12)}$ That investigation showed that steels with a $\mathrm{Ni}$ content lower than around 11 mass \% exhibited hydrogen gas embrittlement (HGE). More precisely, the SUS316-based stainless steels with [Ni] $+0.37[\mathrm{Cr}]<17.5$ mass $\%$ exhibited HGE at room temperature and the ones with $[\mathrm{Ni}]+0.37[\mathrm{Cr}]<17.0 \mathrm{mass} \%$ did so at $-40^{\circ} \mathrm{C}$ at $45 \mathrm{MPa}$ pressure, ${ }^{12)}$ where $[\mathrm{Ni}]+0.37[\mathrm{Cr}]$ is a modified $\mathrm{Ni}$ equivalent related to $\gamma$ phase stability, and [Ni] and $[\mathrm{Cr}]$ are the $\mathrm{Ni}$ and $\mathrm{Cr}$ contents in mass\%. The results substantiated the general thinking that SUS316-based stainless steels with a $\mathrm{Ni}$ content higher than 12 mass $\%$ have strong resistance against hydrogen.

Nomura and Hasegawa ${ }^{15,16)}$ also investigated hydrogen embrittlement of several hydrogen-charged commercial austenitic stainless steels and reported that hydrogen embrittlement strongly depended on the $\mathrm{Ni}$ equivalent ( $\mathrm{Ni}$ eq), ${ }^{17}$ ) which is a function of the chemical composition: $\mathrm{Ni}$ eq $=$ $[\mathrm{Ni}]+0.65[\mathrm{Cr}]+0.98[\mathrm{Mo}]+1.05[\mathrm{Mn}]+0.35[\mathrm{Si}]+12.6[\mathrm{C}]$, where [Ni], [Cr], [Mo], [Mn], [Si] and [C] are, respectively, the Ni, $\mathrm{Cr}, \mathrm{Mo}, \mathrm{Mn}, \mathrm{Si}$ and $\mathrm{C}$ contents in mass $\%$. Zhang et al. ${ }^{18)}$ also used the Ni equivalent as a parameter for HGE of SUS316based stainless steels containing 9.9 to 19.9 mass $\% \mathrm{Ni}$ at temperatures from 80 to $300 \mathrm{~K}\left(-193\right.$ to $\left.27^{\circ} \mathrm{C}\right)$ in $1 \mathrm{MPa}$ hydrogen gas and showed a clear correlation with HGE. Furthermore, Michler et al. ${ }^{19)}$ evaluated HGE of several stainless steels, including type 316, with slightly different chemical compositions at temperatures from -80 to $20^{\circ} \mathrm{C}$ in 10 to 400 bar (around 1 to $40 \mathrm{MPa}$ ) hydrogen gas, and reported that HGE was strongly affected by the chemical composition.

As described above, the chemical composition considerably influences hydrogen embrittlement of stainless steels in the chemical composition range of SUS316, making it important to examine the effects of the contents of major alloying elements on fatigue crack growth properties in high-pressure hydrogen gas.

In the present study, the range of the investigation was widened to include fatigue properties at a higher pressure of $90 \mathrm{MPa}$, somewhat exceeding the maximum approved pres-

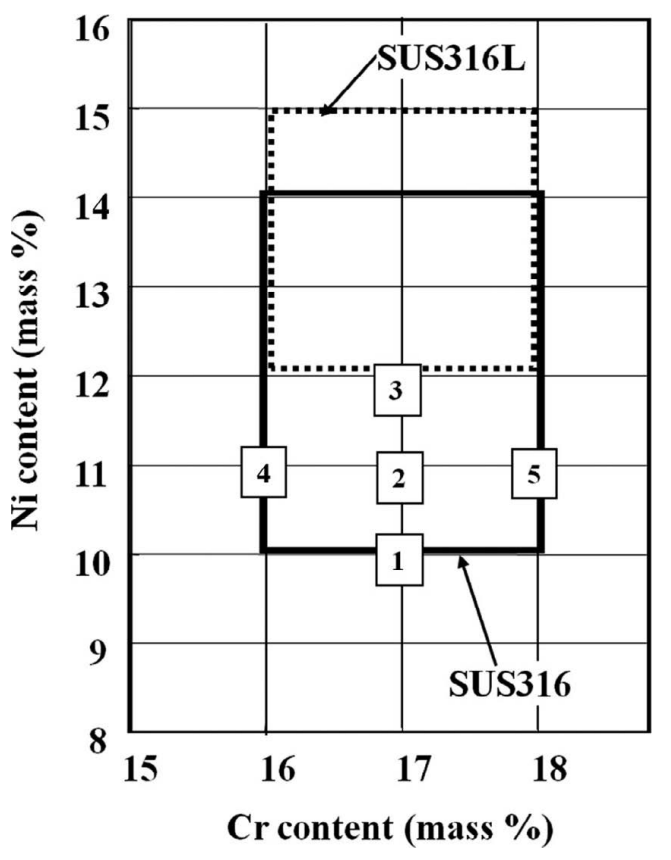

Fig. 1. Ni and $\mathrm{Cr}$ contents of the SUS316-based steels used. JIS composition ranges for SUS316 and SUS316L are also shown.

sure level for $70 \mathrm{MPa}$-class onboard hydrogen fuel vessels so as to take a $25 \%$ fluctuation of the nominal pressure into account. Specially designed facilities for mechanical testing in high-pressure hydrogen gas at up to $99 \mathrm{MPa}^{20,21)}$ were used for characterization of fatigue properties.

\section{Experimental Procedures}

\subsection{Materials Used}

Five kinds of SUS316-based stainless steels listed in Table 1 were used. Their Ni content was from 9.8 to 11.7 mass $\%$, which was less than the lower limit of the JISspecified Ni content range for SUS316L and in the range for SUS316; their Cr content was from 16.1 to 18.1 mass\%, which corresponded to the minimum and the maximum values for SUS316L. The positions of the $\mathrm{Ni}$ and $\mathrm{Cr}$ contents of the tested steels in the JIS content range for SUS316 and SUS316L are shown in Fig. 1. The Mo content was around $2.1 \mathrm{mass} \%$ in all the steels used, and the contents of the other elements, including impurities, were also all the same and in the range of SUS316L.

Ingots weighing $30 \mathrm{~kg}$ and having the compositions shown in Table 1 were prepared by vacuum induction remelting, hot forged and hot rolled into plates of $15 \mathrm{~mm}$ in thickness. The plates were solution treated at $1120^{\circ} \mathrm{C}$ for 5 min followed by water quenching. 
In the following sections, "mass\%" is expressed simply as "\%" for convenience.

\subsection{Fatigue Crack Growth Tests}

As shown in Fig. 2, compact tension (CT) specimens of $12.5 \mathrm{~mm}$ in thickness (B) and $50.0 \mathrm{~mm}$ in width (W) in accordance with American Society for Testing and Materials Standard E647 (ASTM-E647) were used in conducting fatigue crack growth tests. Test specimens were taken from the center of the plate thickness. The crack growth direction was vertical to the rolling direction (parallel to the transverse direction). Fatigue crack growth tests were carried out at room temperature in high-pressure gaseous hydrogen at $90 \mathrm{MPa}$ in accordance with ASTM-E647, using P-constant procedure. The test frequency was $1 \mathrm{~Hz}$ and the stress ratio $\mathrm{R}$ was 0.1 . As mentioned earlier, tests were carried out using specially designed facilities to characterize mechanical properties in high-pressure gaseous hydrogen at pressures up to $99 \mathrm{MPa}$. After the tests, fracture surfaces and nearby cross sections were observed by Scanning Electron Microscopy (SEM), Energy Dispersive Spectroscopy (EDS) and Electron Backscatter Diffraction (EBSD).

\section{Experimental Results and Discussion}

\subsection{Fatigue Crack Growth Rate}

The fatigue crack growth rate of every specimen tested in air is shown in Fig. 3, where the fatigue crack growth rate of commercial SUS316L in air ${ }^{8)}$ is also plotted for comparison, with $\mathrm{Ni}, \mathrm{Cr}$ and Mo contents of 12.1, 17.7 and 2.1\%, respectively. As shown in the graphs, every steel exhibited almost the same da/dN curve, including SUS316L in air, indicating that there was no conspicuous composition dependency of the fatigue crack growth rate in air in the absence of hydrogen.

Test results in $90 \mathrm{MPa}$ hydrogen gas are shown in Figs. 4 and 5, in which the fatigue crack growth rate for one group of three steels containing $17.1 \% \mathrm{Cr}$ and 9.8 to $11.7 \% \mathrm{Ni}$ (steel Nos. 1, 2 and 3 in Table 1) and another group of three steels containing around $10.7 \% \mathrm{Ni}$ and 16.1 to $18.1 \% \mathrm{Cr}$ (steel Nos. 4, 2 and 5 in Table 1), are presented, respectively. In both figures, the fatigue crack growth rate for commercial

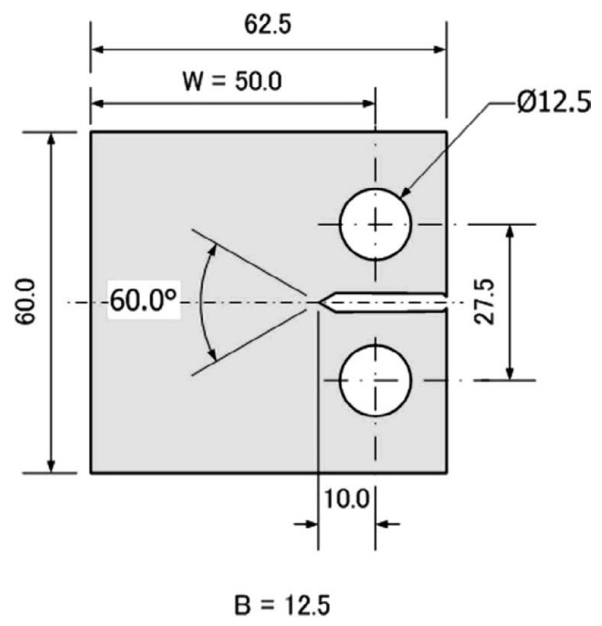

Fig. 2. Dimensions and configuration of $\mathrm{CT}$ specimen with $\mathrm{B}=$ 12.5 and $\mathrm{W}=50.0 \mathrm{~mm}$ used for fatigue crack growth test.
SUS316L in air ${ }^{8)}$ is also plotted as a representative value of the fatigue crack growth rate in air. In addition, the fatigue crack growth rate of SUS304L in $90 \mathrm{MPa}$ hydrogen gas $^{22}$ )
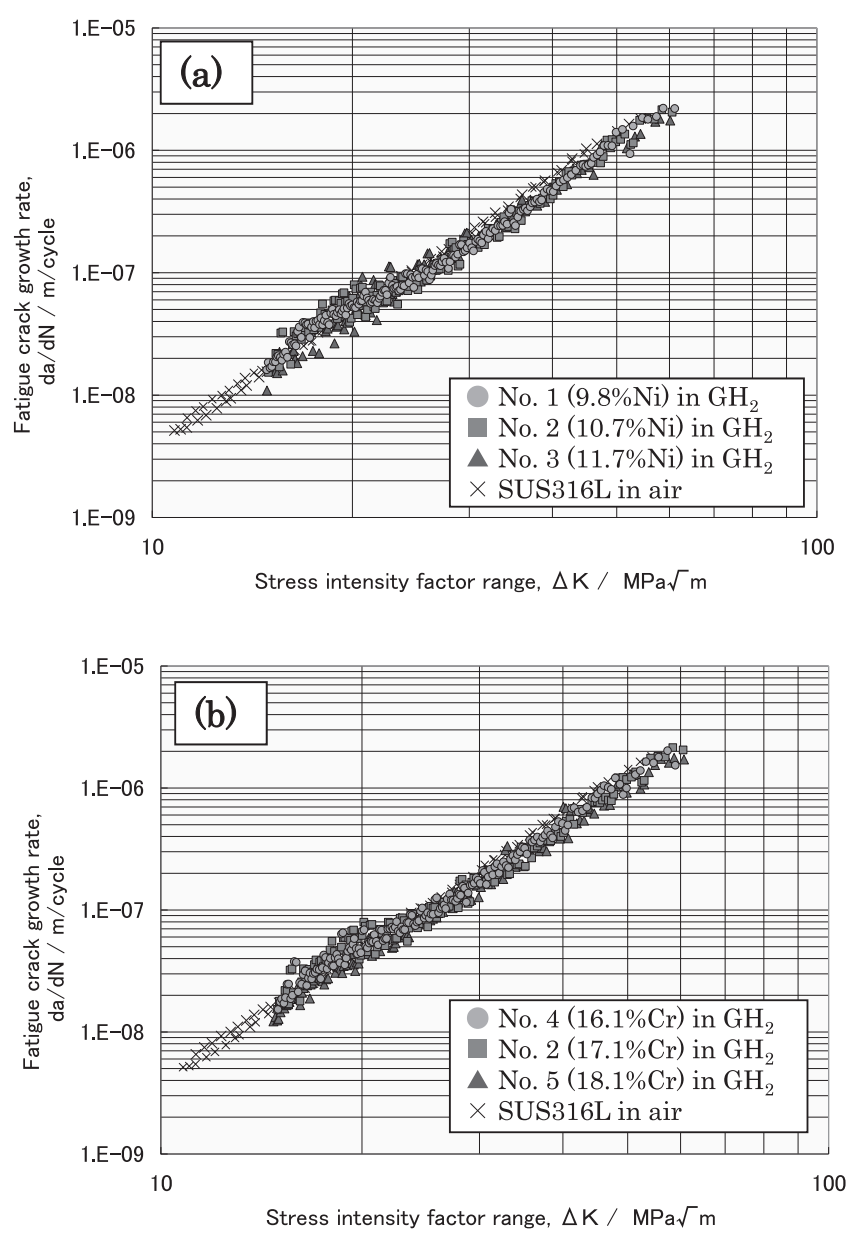

Fig. 3. Fatigue crack growth rate of all SUS316-based stainless steels tested in air at room temperature. The data for SUS316L in air ${ }^{8)}$ are also shown. (a) SUS316-based steels containing $17.1 \% \mathrm{Cr}$ and 9.8 to 11.7 mass $\% \mathrm{Ni}$ (steel Nos. 1, 2 and 3 in Table 1) and (b) SUS316-based stainless steels containing $10.7 \% \mathrm{Ni}$ and 16.1 to 18.2 mass $\% \mathrm{Cr}$ (steel Nos. 4,2 and 5 in Table 1).



Fig. 4. Fatigue crack growth rate of three SUS316-based steels containing $17.1 \% \mathrm{Cr}$ and 9.8 to 11.7 mass\% Ni (steel Nos. 1,2 and 3 in Table 1) in 90 MPa hydrogen gas at room temperature. The data for SUS316L in air ${ }^{8)}$ and SUS304L in $90 \mathrm{MPa}$ hydrogen gas $^{22)}$ are also shown. 


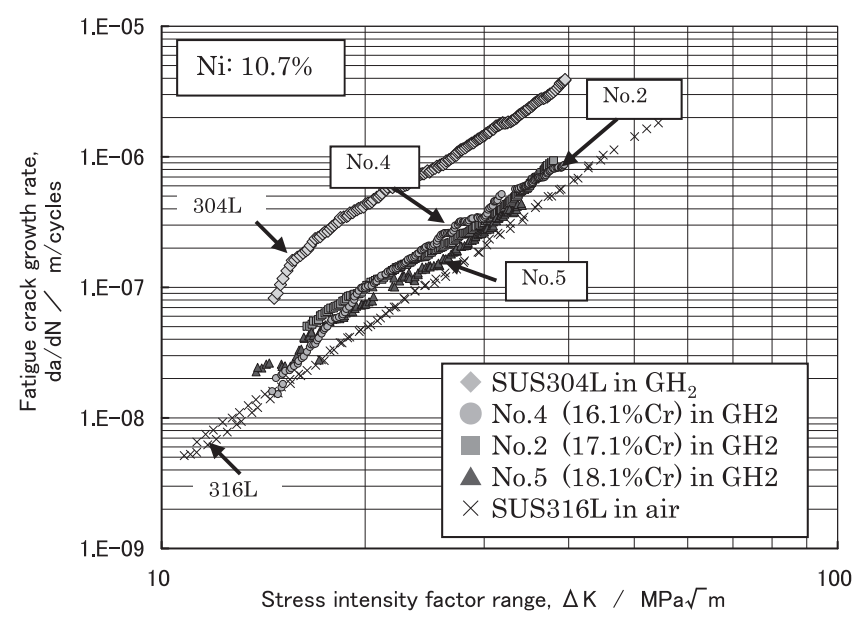

Fig. 5. Fatigue crack growth rate of three SUS316-based stainless steels containing $10.7 \% \mathrm{Ni}$ and 16.1 to $18.2 \mathrm{mass} \% \mathrm{Cr}$ (steel Nos. 4, 2 and 5 in Table 1) in 90 MPa hydrogen gas at room temperature. The data for SUS316L in air ${ }^{8)}$ and SUS304L in $90 \mathrm{MPa}$ hydrogen gas $^{22)}$ are also shown.

is also plotted for comparison, where the $\mathrm{Ni}, \mathrm{Cr}$ and $\mathrm{Mo}$ contents were $9.2,18.3$ and $0.1 \%$, respectively.

As shown in Fig. 4, the fatigue crack growth rate of steel No. 3 containing $11.7 \% \mathrm{Ni}$ in $90 \mathrm{MPa}$ hydrogen gas was very close to that in air, indicating that the effect of highpressure hydrogen gas on the fatigue crack growth rate of this steel specimen was limited. The relatively high Ni content of steel No. 3 was close to the $12 \%$ lower limit prescribed by the relevant JIS for the Ni content of SUS316L. The fatigue crack growth rate for steel Nos. 2 and 3 with lower Ni contents than that of steel No. 1 was accelerated with decreasing Ni content. The fatigue crack growth rate of steel No. $1(9.8 \% \mathrm{Ni})$ was 3 to 4 times higher than that of steel No. $3(11.7 \% \mathrm{Ni})$. The tendency for the fatigue crack growth rate to accelerate in Ni-lean steels agrees with that reported for the degradation of elongation and reduction of area in $45 \mathrm{MPa}$ hydrogen gas. ${ }^{12)}$

It should be noted, however, that the fatigue crack growth rate in steel No. 1 with $9.8 \% \mathrm{Ni}$, which is around 1 mass $\%$ lower than the lower limit of the JIS-specified Ni content range for SUS316L, was much lower than that of SUS304L, indicating that the SUS316L-based stainless steels showed basically higher resistance against hydrogen even though Ni-lean portions were present in the material due to segregation.

The three steels containing $10.7 \% \mathrm{Ni}$ showed similar fatigue crack growth rates in $90 \mathrm{MPa}$ hydrogen gas as seen in Fig. 5, although clear acceleration in steel No. 4 (16.1\% $\mathrm{Cr})$ and No. $2(17.1 \% \mathrm{Cr})$ and slight acceleration in steel No. $5(18.1 \% \mathrm{Cr})$ were observed. These results imply that the $\mathrm{Cr}$ content has an effect on the fatigue crack growth rate inhigh pressure hydrogen gas, although it is considerably smaller than that of the Ni content.

It is known that the fatigue crack growth rate can be expressed by the Paris law ${ }^{23}$ ) for fatigue crack growth, which is an approximation of what is called the second region in the relationship between the fatigue crack growth rate $(\mathrm{da} / \mathrm{dN})$ and the stress intensity factor range $(\Delta \mathrm{K})$, and is expressed as follows:

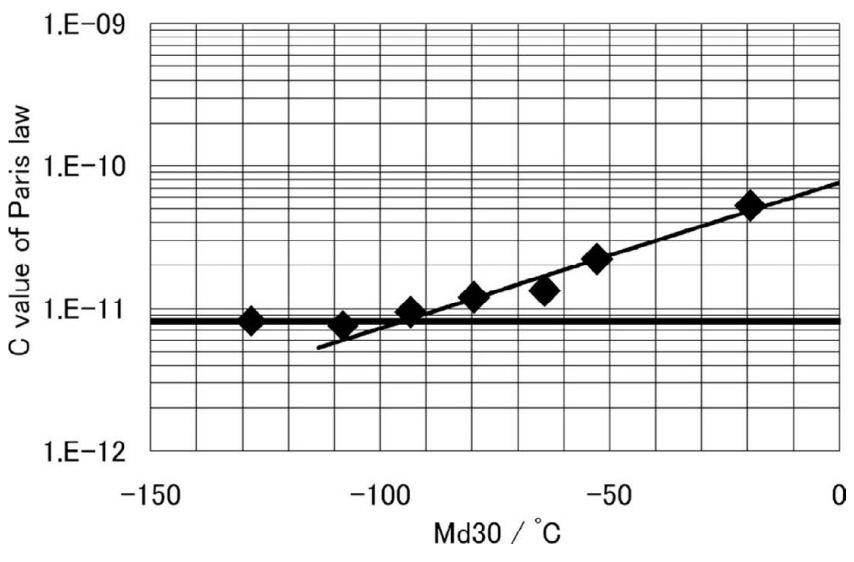

Fig. 6. Effect of $\mathrm{Md} 30$ on $\mathrm{C}$ values in the Paris law for the fatigue crack growth rate $\left(\mathrm{da} / \mathrm{dN}=\mathrm{C}(\Delta \mathrm{K})^{\mathrm{m}}\right)$, where $\mathrm{m}$ is 3 .

$$
\mathrm{da} / \mathrm{dN}=\mathrm{C}(\Delta \mathrm{K})^{\mathrm{m}}
$$

where $\mathrm{C}$ and $\mathrm{m}$ are constants. According to an International Institute of Welding guideline ${ }^{24)}$ for the fatigue design of welded steel structures, the value of $\mathrm{m}$ for steels is 3 . In this study, $\mathrm{C}$ was calculated using the obtained data shown in Figs. 4 and 5 under a condition of $\mathrm{m}=3$ in the $\Delta \mathrm{K}$ range between 20 to $30 \mathrm{MPa} \cdot \mathrm{m}^{1 / 2}$, and used as an index of the fatigue crack growth properties of the steels investigated, including commercial SUS304L and SUS316L in $90 \mathrm{MPa}$ hydrogen gas at room temperature.

In Fig. 6, the values of $\mathrm{C}$ are plotted as a function of $\mathrm{Md} 30,{ }^{25}$ which is an index related to $\gamma$ phase stability against martensite transformation and is believed to be related to HGE. In the steels having high $\gamma$ phase stability with $\mathrm{Md} 30$ lower than $-95^{\circ} \mathrm{C}$, the effect of hydrogen was not observed, and in the steels with $\mathrm{Md} 30$ higher than $-95^{\circ} \mathrm{C}$, the values of $\mathrm{C}$ increased with increasing $\mathrm{Md} 30$, i.e., the fatigue crack growth rate increased with $\mathrm{Md} 30$. In the region of $\mathrm{Md} 30>-95^{\circ} \mathrm{C}$, the relationship between $\mathrm{C}$ and $\mathrm{Md} 30$ can be expressed as

$$
\mathrm{C}=8 \cdot 10^{-11} \cdot \exp (0.0235 \cdot \mathrm{Md} 30) .
$$

A line corresponding to Eq. (2) is also drawn in Fig. 6. By combining Eqs. (1) and (2), the fatigue crack growth rate of the steels having various Md30 in $90 \mathrm{MPa}$ hydrogen gas at room temperature can be estimated, although the application range is limited to the SUS316-based and the SUS304-based stainless steels.

In Fig. 7, the values of $\mathrm{C}$ are plotted as a function of a modified Ni equivalent, $[\mathrm{Ni}]+0.37[\mathrm{Cr}]$, where $[\mathrm{Ni}]$ and $[\mathrm{Cr}]$ are the $\mathrm{Ni}$ and $\mathrm{Cr}$ concentrations, respectively. [Ni] $+0.37[\mathrm{Cr}]$ is an index for HGE in $45 \mathrm{MPa}$ hydrogen gas for SUS316based stainless steels having the same composition, including impurities, as those used in the present study. ${ }^{12)}$ In the region of $[\mathrm{Ni}]+0.37[\mathrm{Cr}]>17.5 \%$, no effect of hydrogen on the values of $\mathrm{C}$ was seen; in the region of $[\mathrm{Ni}]+0.37[\mathrm{Cr}]<$ $17.5 \%$, the values of $\mathrm{C}$ increased with decreasing $[\mathrm{Ni}]+0.37[\mathrm{Cr}]$, i.e., the fatigue crack growth rate increased with decreasing $[\mathrm{Ni}]+0.37[\mathrm{Cr}]$. This tendency is quite similar to ductility loss in $45 \mathrm{MPa}$ hydrogen gas, where HGE occurs in SUS316-based stainless steels with $\mathrm{Ni}$ and $\mathrm{Cr}$ contents of $[\mathrm{Ni}]+0.37[\mathrm{Cr}]<17.5 \%$ at room temperature, ${ }^{12)}$ an index of $[\mathrm{Ni}]+0.37[\mathrm{Cr}]$ seems to be valid for fatigue crack 
growth properties, although the hydrogen gas pressure is higher.

Based on the values of $\mathrm{C}$, degradation of the fatigue crack growth rate in a $90 \mathrm{MPa}$ hydrogen gas environment is depicted in Fig. 8 as a function of the $\mathrm{Cr}$ and $\mathrm{Ni}$ contents. A line for $[\mathrm{Ni}]+0.37[\mathrm{Cr}]=17.5 \%$ is also drawn in the figure.

\subsection{Fracture Surfaces}

SEM images of fracture surfaces are shown in Fig. 9 for steel No. $1(17.1 \% \mathrm{Cr}-9.8 \% \mathrm{Ni})$ and No. $3(17.1 \% \mathrm{Cr}-$

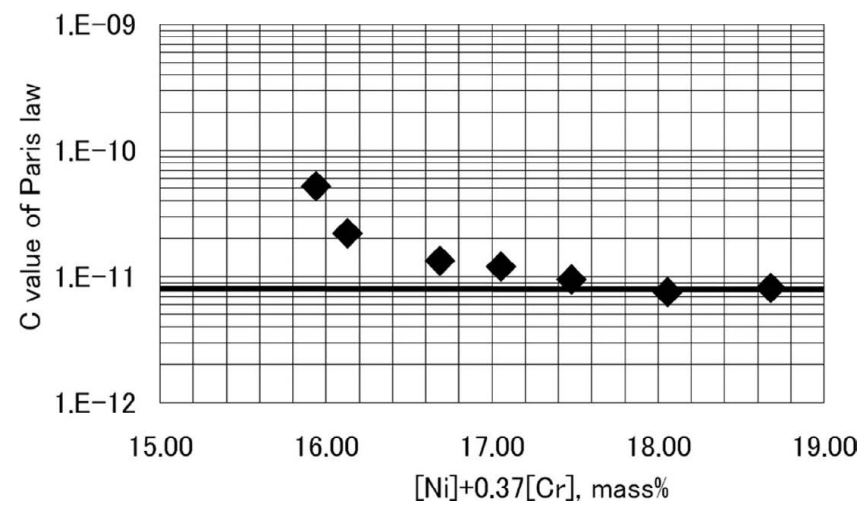

Fig. 7. Effect of modified Ni equivalent, $[\mathrm{Ni}]+0.37[\mathrm{Cr}]$, on $\mathrm{C}$ values in the Paris law for the fatigue crack growth rate . [Ni] and $[\mathrm{Cr}]$ are the $\mathrm{Ni}$ and $\mathrm{Cr}$ contents, respectively.

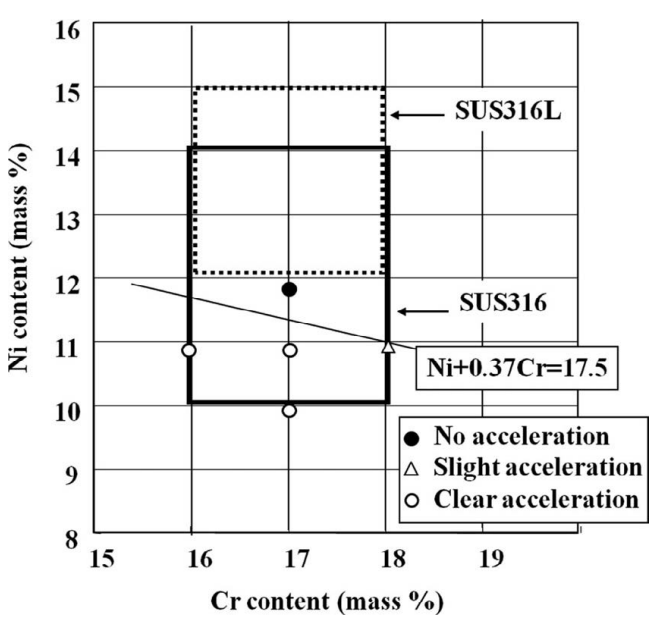

Fig. 8. Relationship between degradation of fatigue crack growth properties in $90 \mathrm{MPa}$ hydrogen gas at room temperature and $\mathrm{Ni}$ and $\mathrm{Cr}$ contents in the SUS316-based stainless steels.
$11.7 \% \mathrm{Ni}$ ), which exhibited the highest and lowest fatigue crack growth rate, respectively. The observation was conducted for the area corresponding to around $25 \mathrm{MPa} \cdot \mathrm{m}^{1 / 2}$ of $\Delta \mathrm{K}$. Almost the entire fracture surface of both steels was typical of fatigue fracture. However, some faceted areas were also observed in both steels. More faceted areas were observed in steel No. 1 than in steel No. 3 with a higher Ni content. EDS analyses revealed that the faceted areas contained the same levels of $\mathrm{Ni}, \mathrm{Cr}$ and $\mathrm{Mo}$ as in the other areas, indicating that the faceted areas were not the $\delta$ ferrite phase, which is sometimes contained in austenitic stainless steels in small amounts.

Figure 10 shows phase images obtained by EBSD analyses for cross sections near the fracture surfaces of steel Nos. 1 and 3; the former showed the highest fatigue crack growth rate among the steels used and the latter showed no effect of hydrogen on the fatigue crack growth rate. The observation was again conducted for the area corresponding to around $25 \mathrm{MPa} \cdot \mathrm{m}^{1 / 2}$ of $\Delta \mathrm{K}$.

As shown in Figs. 10(a) and 10(b), a small amount of the bcc phase ( $\alpha^{\prime}$ martensite) was observed along the fracture surface and adjacent areas of sub-cracks in steel No. 1. However, it should be noted that the formation of $\alpha^{\prime}$ martensite was limited, and most of the area on the fracture surface was the parent $\gamma$ phase. This suggests that the fatigue cracks propagated mainly in the $\gamma$ phase. It is not likely that cracks always propagate in the hydrogen-embrittled $\alpha^{\prime}$ martensite phase formed near the crack tip prior to crack propagation. No clear $\alpha^{\prime}$ martensite phase was observed in steel No. 3 with a higher Ni content as shown in Fig. 10(c).

Figure 11 shows the results of EBSD analyses for faceted areas in the fracture surfaces of steel No. 1. Figure 11(a) presents the results for a faceted area that was roughly parallel to the bottom surface of the specimen used for the observation. The $\alpha^{\prime}$ martensite phase was not clearly seen in the faceted surface. However, the $\gamma$ phase having the fcc structure was clearly observed and it was close to the $\{111\}$ $\gamma$ plane. Figure 11(b) shows the results for a faceted surface that was inclined at around $35^{\circ}$ to the bottom surface of the specimen. Most of the faceted area was the $\gamma$ phase, and by taking into account the inclined angle of $35^{\circ}$, it was close to the $\{111\} \gamma$ plane. These observation results are consistent with those shown in Fig. 11(a). In this case, the $\alpha^{\prime}$ martensite phase having the bcc structure was also observed, which indicates that the faceted surface was composed of the

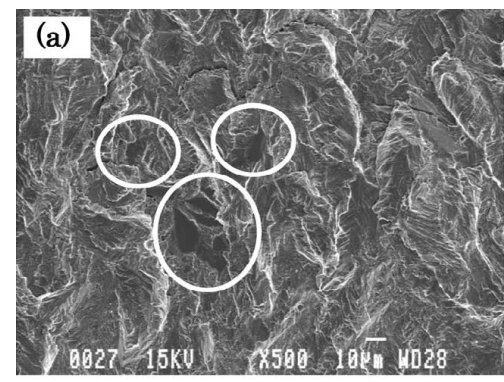

30um

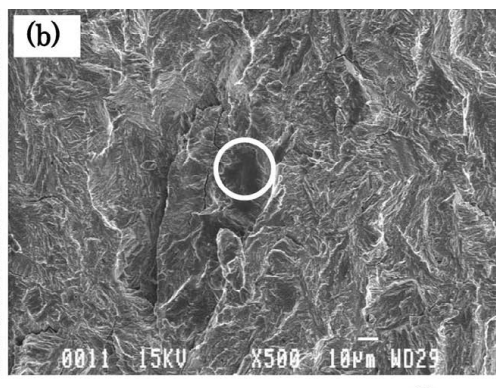

Fig. 9. SEM images of fracture surfaces of (a) steel No. 1 (17.1\% Cr-9.8\% Ni) and (b) steel No. $3(17.1 \% \mathrm{Cr}-11.7 \% \mathrm{Ni})$, tested in gaseous hydrogen at $90 \mathrm{MPa}$. Circles in the photographs indicate faceted fracture surfaces. Observed positions correspond to those of around $25 \mathrm{MPa} \cdot \mathrm{m}^{1 / 2}$ of $\Delta \mathrm{K}$. 
(a)

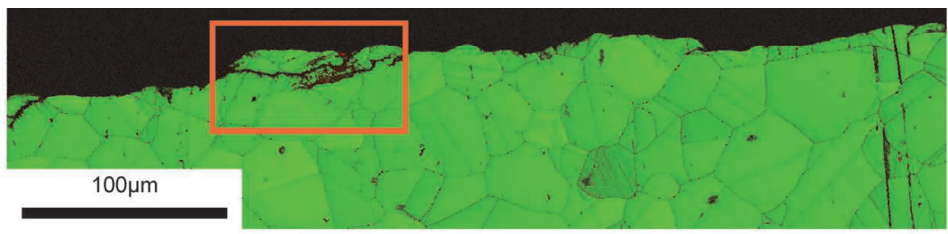

(b)

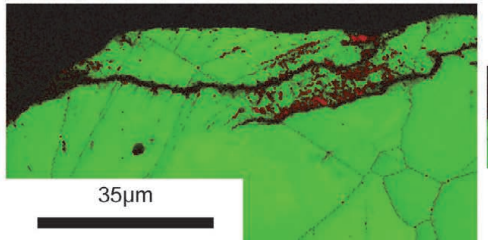

(c)



Fig. 10. Phase images obtained by EBSD for cross section near the fracture surfaces. (a) and (b) steel No. $1(17.1 \% \mathrm{Cr}-$ $9.8 \% \mathrm{Ni})$ and (c) steel No. $3(17.1 \% \mathrm{Cr}-11.7 \% \mathrm{Ni})$. (b) is an enlarged image of the area in the rectangle in (a). Fatigue crack growth test was conducted in gaseous hydrogen at $90 \mathrm{MPa}$. Observed positions correspond to those of around $25 \mathrm{MPa} \cdot \mathrm{m}^{1 / 2}$ of $\Delta \mathrm{K}$.

(a)
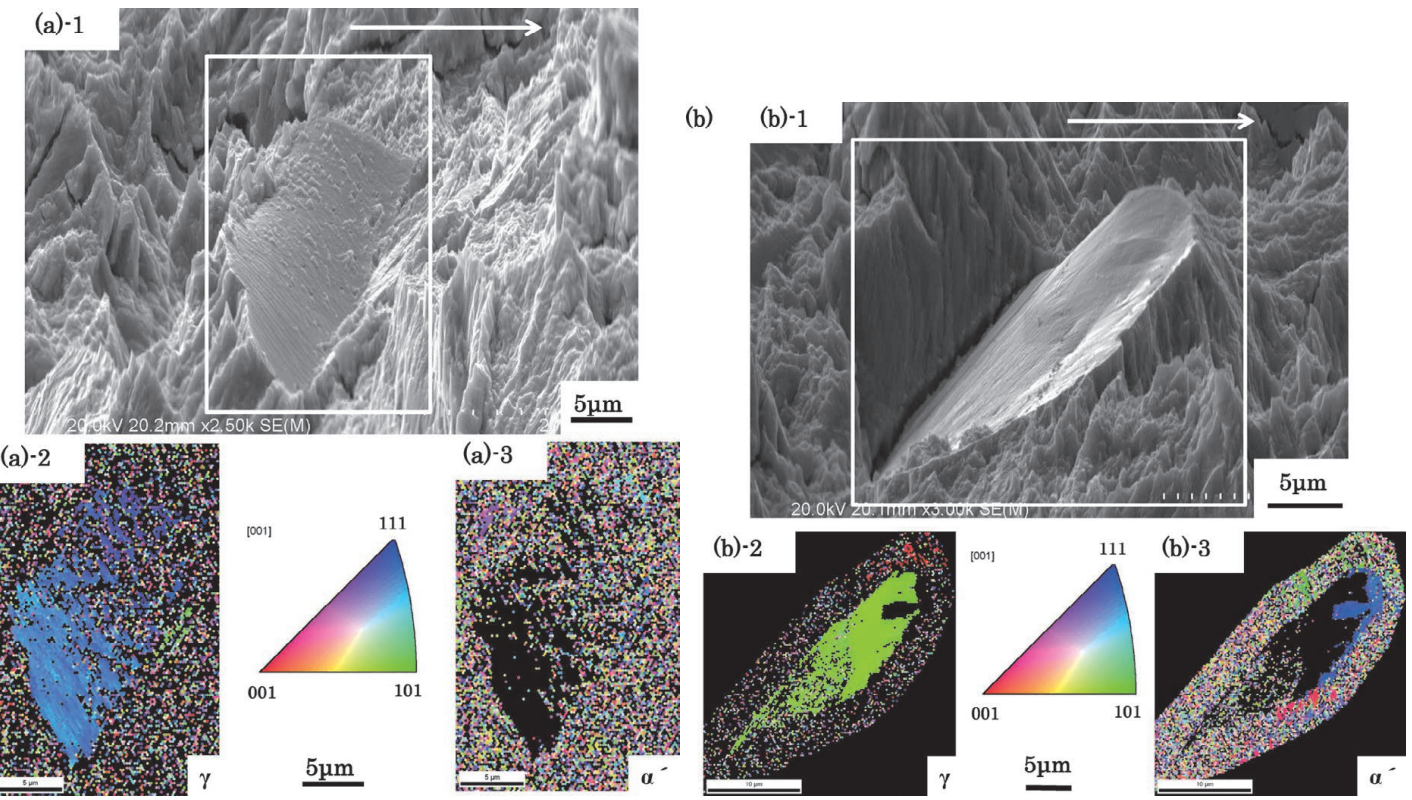

Fig. 11. Microscopic observation by EBSD of the faceted areas on the fracture surface shown in Fig. 9(a) for steel No. 1 $(17.1 \% \mathrm{Cr}-9.8 \% \mathrm{Ni})$. ND (normal direction) is roughly normal to the bottom surface of the observed specimen and macroscopic fracture surface. Observations were conducted for two areas, (a) and (b). In area (a), the faceted surface is roughly parallel to the bottom surface of the observed specimen as well as the macroscopic fracture surface, and in area (b), the faceted surface is inclined by about $35^{\circ}$ to the bottom surface of the observed specimen and macroscopic fracture surface. (a) -1 and (b)- 1 are SEM images, in which the arrow shows the macroscopic direction of fatigue crack propagation and the rectangle indicates the area of the EBSD analysis. (a)-2 and (b)-2 are the fcc $\gamma$ phase map, and (a)-3 and (b)-3 are the bcc $\alpha$ phase map. Colors in the phase maps correspond to the crystallographic orientations depicted in the standard stereographic projection for cubic structures.

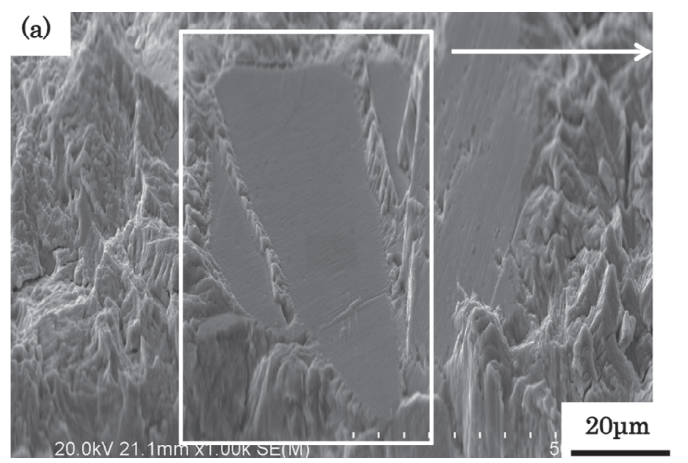

(b)

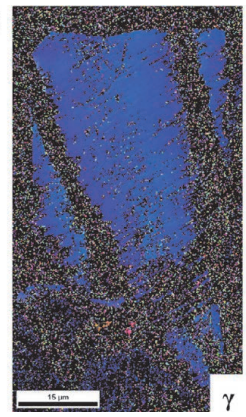

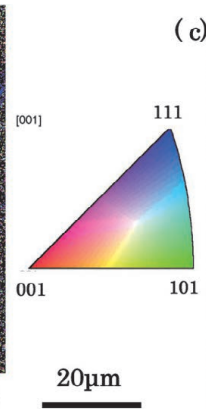

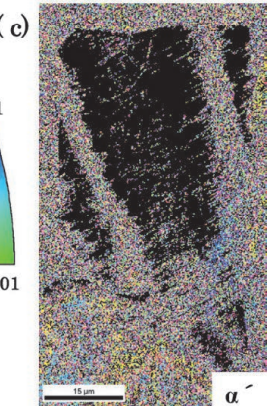

Fig. 12. Microscopic observation by EBSD of the faceted area on the fracture surface shown in Fig. 9(b) for steel No. 3 $(17.1 \% \mathrm{Cr}-11.7 \% \mathrm{Ni})$. ND is roughly normal to the bottom surface of the observed specimen, macroscopic fracture surface and faceted surface. (a) SEM image in which the arrow shows the macroscopic direction of fatigue crack propagation and the rectangle indicates the area of the EBSD analysis. (b) and (c) are the phase maps for fcc $\gamma$ and bec $\alpha^{\prime}$, respectively. Colors in the phase maps correspond to the crystallographic orientations depicted in the standard stereographic projection for cubic structures. 

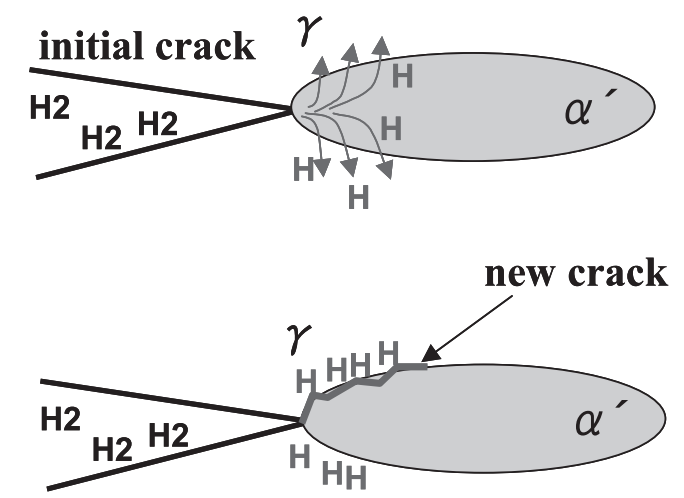

Solubility of $\mathbf{H}: \gamma>>\boldsymbol{\alpha}^{-}$

Diffusion of $\mathbf{H}: \gamma<<\boldsymbol{\alpha}^{-}$

Fig. 13. Schematic representation of presumed formation mechanism of hydrogen concentrated area along the $\gamma$ and $\alpha^{\prime}$ phase boundary which may serve as the path of fatigue crack propagation. ${ }^{30)}$

$\{111\} \gamma$ plane and the $\alpha^{\prime}$ martensite phase. The same results were obtained for other faceted areas observed without exception.

The results of EBSD analyses for a faceted area in the fracture surface of steel No. 3 and roughly parallel to the bottom surface of the specimen are shown in Fig. 12. Most of the faceted area was the $\{111\} \gamma$ plane. In this case, the $\alpha^{\prime}$ martensite phase was not clearly observed.

Similar faceted fracture surfaces were reported by Caskey, ${ }^{26)}$ who suggested that annealing twin boundaries are the preferential sites for martensite, which also leads to preferential crack growth along the $\gamma / \alpha^{\prime}$ boundaries. Fukuyama et $a .^{27)}$ observed faceted fracture surfaces consisting of $\{111\} \gamma$ in tensile test specimens of SUS304 tested in hydrogen gas and also indicated that the faceted surface was twin boundaries. They found similar faceted fracture surfaces called a "plate-like pattern" in fatigue test specimens of type 304 stainless steel tested in 4.0 MPa hydrogen gas at room temperature. ${ }^{28)}$ Ulmer et al. ${ }^{29)}$ also obtained similar results for hydrogen-charged 304 and 310S type stainless steels. The authors have also observed faceted fracture surfaces in fatigue crack growth test specimens of SUS304L tested at room temperature in $45 \mathrm{MPa}$ hydrogen gas. ${ }^{30)}$

It is natural to think that the formation mechanism of such faceted fracture surfaces, basically composed of $\{111\} \gamma$ and $\alpha^{\prime}$ martensite, is the same in both the SUS304L-based steels evaluated in our previous study ${ }^{30}$ and the SUS316-based stainless steels evaluated in this study. Although clear evidence of $\alpha^{\prime}$ martensite was not confirmed by EBSD in steel No. 3 as shown in Fig. 12, it is likely that some areas with a slightly lower Ni content as a result of segregation may have undergone martensite transformation accompanying fatigue crack propagation. Annealing twin boundaries, which Caskey ${ }^{26)}$ suggested as the preferential sites for martensite transformation, did not seem to form the martensite phase in this study as shown in Fig. 10(b).

Based on our previous report, ${ }^{30)}$ the formation mechanism of faceted fracture surfaces composed of $\{111\} \gamma$ and $\alpha^{\prime}$ martensite is considered as follows:

Once $\alpha^{\prime}$ martensite forms near the crack tip, hydrogen atoms are absorbed in the matrix from the outside hydrogen
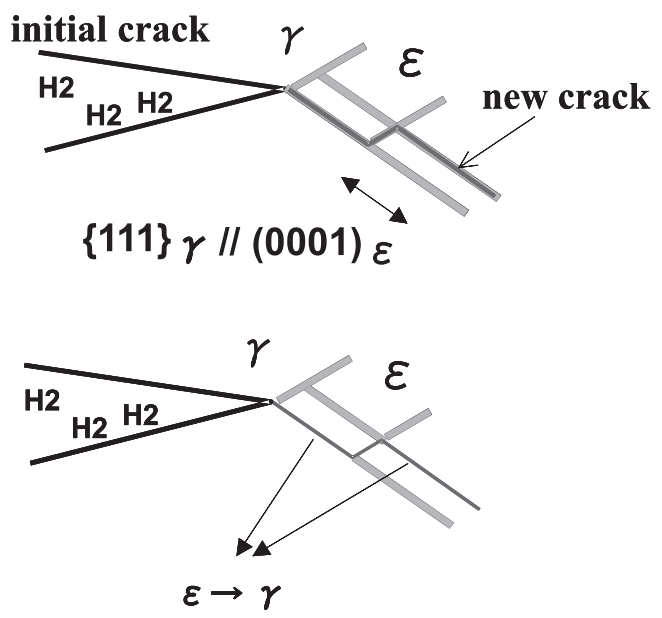

Fig. 14. Schematic representation of presumed formation mechanism of faceted fracture surfaces containing the $\{111\} \gamma$ plane. $^{30)}$

gas environment and move rapidly toward the adjacent $\gamma$ phase, because hydrogen solubility in the $\gamma$ phase is much higher than in the $\alpha^{\prime}$ martensite phase. On the other hand, hydrogen diffusivity is much higher in $\alpha^{\prime}$ martensite than in the $\gamma$ phase. As a result, the hydrogen concentration may increase along the $\alpha^{\prime} / \gamma$ phase boundaries. This situation is shown schematically in Fig. 13. ${ }^{30)}$ If cracks propagate in this high hydrogen content area, fracture surfaces composed of both the $\alpha^{\prime}$ and $\gamma$ phases are generated. The reason why $\{111\} \gamma$ becomes the fracture surface is not clear. However, $\mathcal{E}$ martensite with a planer configuration was observed in SUS304L, ${ }^{30)}$ and it is likely that the hydrogen-embrittled $\varepsilon$ martensite phase reverted to the $\gamma$ phase after the crack propagated. This situation is shown schematically in Fig. 14, ${ }^{30}$ where the fracture along $(0001) \varepsilon$ may leave the $\{111\} \gamma$ fracture surface.

\section{Conclusions}

Fatigue crack growth tests in high-pressure gaseous hydrogen at $90 \mathrm{MPa}$ were carried out for SUS316-based stainless steels containing $16.1-18.1 \% \mathrm{Cr}$ and $9.8-11.8 \%$ $\mathrm{Ni}$, and the effects of the major alloying elements, $\mathrm{Ni}$ and $\mathrm{Cr}$, on fatigue crack propagation were investigated. The major results obtained are as follows:

(1) The fatigue crack growth rate of SUS316-based steels with a Ni content lower than 12 mass $\%$ was accelerated in $90 \mathrm{MPa}$ hydrogen gas at room temperature with decreasing Ni content, although it was much less than that of SUS304L.

(2) The Cr content also affects the fatigue crack growth rate in hydrogen gas, although its effect is considerably less than that of the Ni content.

(3) The combined effect of the $\mathrm{Ni}$ and $\mathrm{Cr}$ contents on the fatigue crack growth rate in $90 \mathrm{MPa}$ hydrogen gas was closely related to $\mathrm{Md} 30$ and $[\mathrm{Ni}]+0.37[\mathrm{Cr}]$, where $[\mathrm{Ni}]$ and $[\mathrm{Cr}]$ are the $\mathrm{Ni}$ and $\mathrm{Cr}$ contents, respectively. The fatigue crack growth rate in the second region in the da/ $\mathrm{dN}-\Delta \mathrm{K}$ relationship for SUS316-based stainless steels can be estimated with the Paris equation, $\mathrm{da} / \mathrm{dN}=\mathrm{C}(\Delta \mathrm{K})^{\mathrm{m}}$, and $\mathrm{C}=8 \cdot 10^{-11} \cdot \exp$ $(0.0235 \cdot \mathrm{Md} 30)$ in steels with $\mathrm{Md} 30>-95^{\circ} \mathrm{C}$. 
(4) No clear degradation of the fatigue crack growth rate due to a high-pressure hydrogen gas environment occurred in SUS316-based steels with $\mathrm{Md} 30 \leq-95^{\circ} \mathrm{C}$ or $[\mathrm{Ni}]+0.37[\mathrm{Cr}] \geq 17.5$ mass $\%$.

(5) Fatigue cracks propagate mainly in the $\gamma$ phase, and the $\alpha^{\prime}$ deformation induced martensite phase sometimes becomes the crack propagation path in steels with low $\gamma$ phase stability. Faceted fracture surfaces formed in every steel tested, and the density of the faceted surface was higher in the steels with low $\gamma$ phase stability.

(6) The faceted fracture surfaces were composed of the $\{111\} \gamma$ plane and $\alpha^{\prime}$ martensite and considered to be formed as a result of hydrogen gas embrittlement at or near the interphase boundaries between the two phases, where the hydrogen concentration was considered to be high.

\section{Acknowledgement}

The study was commissioned by the New Energy and Industrial Technology Development Organization (NEDO) as part of a project for the Establishment of Codes \& Standards for the Hydrogen Economy Society, with funding from the Ministry of Economy, Trade and Industry (METI) of Japan. The authors would like to express their gratitude to Drs. K. Yokogawa and S. Fukuyama, AIST, for fruitful discussions on faceted fracture surfaces.

\section{REFERENCES}

1) http://fccj.jp/pdf/22_csj.pdf: Fuel Cell Commercialization Conf. of Japan, Tokyo, (2010).

2) R. J. Walter and W. T. Chandler: NASA contractor report, Influence of Gaseous Hydrogen of Metals, NASA-CR-124410, Rockwell Int., Rocketdyne, (1973).

3) R. P. Jewett, R. J. Walter, W. T. Chandler and R. P. Frobmerg: NASA contractor report, Hydrogen Environment Embrittlement of Metals, NASA-CR-2163, North American Rockwell, Rocketdyne, (1973).

4) W. T. Chandler and R. J. Walter: ASTM STP543, ed. by L. Raymond, ASTM, Philadelphia, PA, (1974), 170.

5) J. A. Harris, Jr. and W. C. Van Wanderham: ASTM STP543, ed. by L. Raymond, ASTM, Philadelphia, PA, (1974), 198.
6) S. Ohmiya and H. Fujii: Proc. of Hydrogen and Fuel Cell Futures Conf., Government of Western Australia Department for Planning and Infrastructure, Western Australia, (2004), CD-ROM.

7) S. Ohmiya and H. Fujii: ASME PVP2005-71735, American Society of Mechanical Engineers, New York, (2005), CD-ROM.

8) S. Ohmiya and H. Fujii: ASME PVP2007-26492, American Society of Mechanical Engineers, New York, (2007), CD-ROM.

9) S. Ohmiya and H. Fujii: CAMP ISIJ, 21 (2008), 1285 (in Japanese), CD-ROM.

10) JARI S001, JARI S002: Japan Automobile Research Institute, Ibaraki, (2004).

11) KHK S0128: The High Pressure Gas Safety Institute of Japan, Tokyo, (2010).

12) H. Fujii and S. Ohmiya: J. High Pressure Inst. Jpn., 47 (2009), 85 (in Japanese).

13) T. Watanabe, N. Takano and H. Fujii: J. High Pressure Inst. Jpn., 47 (2007), 78 (in Japanese).

14) T. Michler, Y. Lee, R. P. Gangloff and J. Naumann: Int. J. Hydrogen Energy, 34 (2009), 3201.

15) S. Nomura and M. Hasegawa: Bull. Jpn. Inst. Met., 15 (1976), 563 (in Japanese).

16) S. Nomura and M. Hasegawa: Tetsu-to-Hagané, 64 (1978), 288 (in Japanese).

17) T. Hirayama and M. Ogirima: J. Jpn. Inst. Met., 34 (1970), 507 (in Japanese).

18) L. Zhang, M. Wen, M. Imade, S. Fukuyama and K. Yokogawa: Acta Mater., 56 (2008), 3414

19) T. Michler, A. A. Yukhimchuk and J. Naumann: Corros. Sci., 50 (2008), 3519.

20) H. Fujii, S. Ohmiya and T. Kayama: Proc. of 16th World Hydrogen Energy Conf., International association for hydrogen energy. Florida, (2006), CD-ROM.

21) S. Ohmiya and H. Fujii: Proc. of 17 th World Hydrogen Energy Conf., CD-ROM, (2008).

22) S. Ohmiya and H. Fujii: Proc. of ISIJ symp. on "Fundamental Construction for Hydrogen Embrittlement", ISIJ, Tokyo, (2011), 41.

23) P. C. Paris and F. Erdogan: J. Basic Eng., 87 (1960), 528.

24) A. Hobbacher: IIW doc. XIII-1965-03/XV-1127-03, International Institute of Welding, Paris, (2005), 91.

25) K. Nohara, H. Ono and N. Ohashi: Tetsu-to-Hagané, 63 (1977), 772.

26) G. R. Caskey, Jr.: Environmental degradation of engineering materials in hydrogen, ed. by M. R. Louthan, Jr., R. P. McNitt and R. D. Sisson, Jr., Virginia Polytechnic Institute, Virginia, (1981), 283.

27) S. Fukuyama, L. Zhang, M. Wen and K. Yokogawa: J. Jpn. Inst. Met., 67 (2003), 157 (in Japanese).

28) S. Fukuyama, K. Yokogawa, K. Kudo and M. Araki: Trans. Jpn. Inst. Met., 26 (1985), 325.

29) D. G. Ulmer and C. J. Altstetter: Acta Metall., 39 (1991), 1237.

30) H. Fujii and S. Ohmiya: Proc. of 2nd Int. Symp. on Steel Science, ISIJ, Tokyo, (2009), 175. 